\title{
Computerized Summative Assessment of Multiple-choice Questions: Exploring Possibilities with the Zimbabwe School Examination Council Grade 7 Assessments
}

\author{
Benjamin Tatira (Corresponding author) \\ Mokutu Secondary School \\ P.O. Box 253, Molototsi 0827, Republic of South Africa \\ E-mail: bentatira@yahoo.com \\ Lillias Hamufari Natsai Mutambara \\ Bindura University of Science Education \\ P Bag 2010, Bindura, Zimbabwe \\ E-mail: 1hnmutambara@yahoo.co.uk \\ Conilius J. Chagwiza \\ Bindura University of Science Education \\ P Bag 1020, Bindura, Zimbabwe \\ E-mail: cjchagwiza@gmail.com \\ Lovemore J. Nyaumwe \\ University of South Africa, College of Education \\ P.O. Box 392, UNISA 0003, Republic of South Africa \\ E-mail: nyauml@unisa.ac.za
}

Received: August 16, 2011

Accepted: September 15, 2011

Published: November 1, 2011

doi:10.5539/cis.v4n6p66

URL: http://dx.doi.org/10.5539/cis.v4n6p66

\begin{abstract}
The purpose of this study was to develop educational software for online assessment of multiple choice responses (MCQs). An automated assessment software program, duly developed in this study can display assessment items, record candidates' answers, and mark and provide instant reporting of candidates' performance scores. Field tests of the software were conducted on four primary schools located in Bindura town using a previous year summative Grade 7 assessment set by the Zimbabwe School Examination Council (ZIMSEC). Results were that computerized assessment in mathematics has the potential to enhance the quality of assessment standards and can drastically reduce material costs to the examination board. The paper exposes test mode benefits inherent in computer-based assessments, such as one-item display and ease of candidates selecting/changing optional answers. It also informs the ongoing debate on possible enhancement of candidates' performance on a computer-based assessment relative to the traditional pen-and-paper assessment format. The need for the development of diagnostic instructional software to compliment computerized assessments is one of the recommendations of the study.
\end{abstract}

Keywords: Computer-based Tests, Mathematics Assessment, Multiple-choice Questions, Online Assessment, Software Programming

\section{Introduction}

In the Zimbabwean education system, all the summative examination papers set by the Zimbabwe School Examination Council (ZIMSEC) are conducted in paper-based format. Under that system, challenges have 
recently emerged whereby examination papers have leaked before the examination date, administration costs have skyrocketed and the manual assessment of the multiple-choice questions (MCQs) have been blamed for causing untold delays in the publication of results. In line with modern developments in science and technology, computer programs have the potential to alleviate some of these challenges at a minimum cost. A well-designed computer program can display the assessment tasks to candidates, mark the responses, grades responses, records, and instantly provide feedback on the performance of each candidate. Moreover, a series of password codes can completely bar unauthorized entry to the assessment tasks to those with intents to temper with candidates' scores.

In recent years, computer-based assessments have grown in popularity internationally and are increasingly being used in developed countries. Due to their accuracy and speed of execution they are predicted to become the primary mode of assessment in the future (Wang, Jiao, Young, Brooks \& Olson, 2007). Modern technologies have generally been accepted in almost every facet of society, which in turn have made people's lives much easier and enjoyable to live. Nobody would dare think of any meaningful life on this planet without mobile phones, the Internet, Compact Disks and satellite televisions as instant sources of information and entertainment. Mathematicians world-wide likewise stress the need to adapt towards an ever-changing technological society (Brumbaugh \& Rock, 2001) so as to keep abreast with the changing technological times. Computer technology has for a long time been an asset in the workplace, homes and schools in Zimbabwe and other countries. However, computers in Zimbabwean schools are grossly under-utilised (Cawthera, 2005), amounting to about 20 $-30 \%$ of their potential optimal use. Schools' emphasis has often been on computer literacy courses to learners and for school administrative purposes, with little regard to subject-specific instructional purposes. It is high time that educators make inroads into content-specific software development for the classroom, if ever mathematics content in particular, has to live up to the expectations of modern technologies in the wider society.

The Zimbabwean mathematics curriculum, which is predominantly examination-oriented, commands a credible assessment system which uses multiple evaluation strategies. It incorporates multiple techniques of assessment such as MCQs and problem-solving tasks that require reasoning through several solution steps, [which include, inter-alia, written, practical, demonstration and computer-based tests (Brown, 2000). Computer-based assessments, though not widely used in Zimbabwe, are recent and innovative, which warrants a serious scrutiny on their possible development and implementation in a national examination system such as ZIMSEC examination. Transforming an existing pen-and-paper-based summative assessment to computerized format for the national MCQs using online techniques can produce efficiency and accuracy in the administration of the assessments. This is possible because a computer program is highly capable of assessing questions containing pre-determined answers as in MCQs. Such a program can reliably and consistently execute a set of tasks repeatedly without weariness or bias over the several thousand candidates who can sit for summative assessments annually. Hence computer-mediated assessment is highly reliable and consistent (Scholtz, 2007) unlike human assessments that are influenced by an assessor's mood, interpretation and understanding. The present study was motivated by the need to improve summative MCQ assessments in Zimbabwe through reducing as much as possible any human factors that may obscure a candidate's true achievement. The study attempts to contribute to this goal by developing software to assess Grade 7 MCQs after piloting it on Grade 7 Mathematics Paper 1 responses. Such software can contribute to attempts in Zimbabwe to improve the reliability, consistency, fairness, utility and credibility of mathematics assessments (Bennett, 1998).

Beginning as far back as primary school level, learners usually start displaying effects of mathematics-phobia arising from long tedious procedures that they learn through regurgitation. This practice has high possibility of devastating effects that can make learners develop negative attitudes towards the subject. Socially responsible mathematics educators can do justice to the learning of the subject if they attempt to come up with innovative assessment strategies that have the effect of motivating learners to learn the subject and counter mathematics-phobia in the process. A study by McIntosh and Stacey (2000) showed that computer use in mathematics education can heighten learners' interest in the subject. It was also noted that from a candidate's perspective, computer-based assessments are easier to understand (Wang, Jiao, Young, Brooks \& Olson, 2007) and candidates complete them faster than hand-written ones (Truell, Alexander and Davis, 2004). Furthermore, handwritten assessments are reviled as boring by most candidates (Brown, 2000), hence the necessity to start expanding assessment methods to technology-based formats. With the recent technological changes world-wide, administration of assessments can even be done over the internet, thereby eliminating the need for bulk shipping, warehousing and printing massive amounts of examination papers.

Currently, MCQ answer scripts for ZIMSEC are read mechanically and marked by optical scanner readers. However, it has been reported that these machines are now obsolete, and worse still, spare parts for servicing them are no longer available on the local market because manufacturers are not finding easy markets for them. 
The lack of service to the optical scanner machines of necessity means that a few of them are available for large quantities of MCQs assessment responses, resulting in delays in processing results. Explaining the delay of publishing summative Grade 7 results, the ZIMSEC Director argued that, "unless we have a scanner which can mark the whole paper consisting of 50 questions at a fraction of a second, assessment cannot not be fast. On the other hand, if we use manual marking it will take ages, costs a lot of money and it will require a lot of labour," (Zimonline, 2007). The development and use of purpose-made software programs potentially alleviates problem of processing of results by expediting the entire examination procedure. This study was an attempt to explore a possible way of assessing MCQs in a fast and efficient way. The study was guided by the research question: Can Zimbabwean basic computer software be developed to assess computer- based MCQ responses and can such software be effective and reliable to display a candidate's performance? Answers to this question can contribute to the current debate on the effective use of technology in assessment.

\section{Theoretical Framework}

A research by Linn (2002) noted that in Zimbabwe the greatest barrier to reform teaching is assessment that measures today's skills using yesterday's testing means. What is required to align today's skills with assessment methods are innovative and interactive assessment tools compatible with the current times that learners are experiencing. The world of work has been revolutionized by technology and computerization, to the extent that effective preparation of learners for the 21 st Century workplace should not ignore technology in the classroom if such learners are to be relevant on the current job market. One successful way to actively engage learners in their learning is to design and develop software programs specific and relevant to the mathematics curriculum. Robust assessments can be put in place to measure their achievements. A robust assessment is needed for accountability purposes through providing timely evidence of learning to the stakeholders. Furthermore, valid and transparent assessment methods are necessary and vital to the learning process as they can present irrefutable testimony to the extent to which learning has occurred (Kubiszu \& Borich, 1993). Broadening the scope of assessment to include computerized assessment may increases the validity and reliability of such testing. Though pen-and-paper assessments dominate the educational landscape in Zimbabwe and other developing countries, advancements in technology dictate educators to start reviewing assessment strategies to make them aligned to the lived experiences of learners.

This study was an attempt towards reducing the gap between mathematics summative assessment and technology in education in Zimbabwe. The contribution was made through designing and developing a software program for assessing MCQs and field testing it on selected schools in Zimbabwe. Generally, computerized achievement assessments are conspicuous by their absence in the educational landscape in Zimbabwe. The standardized skills tests for international programs like the Test for English Language as a Second Language and Graduate Record Examination are available in the country, but currently are externally controlled. However, the thorny issue is; can mathematics classrooms be able to use such computer programs for local educational purpose. By administering the same test in pen-and-pencil and computer based modes, Wang, Jiao, Young, Brooks and Olson (2007) discovered that computer-based tests do not yield equivalent scores with their paper-based counterparts. It points to the existence of assessment mode benefits for computer-based assessment, some of which would be contextually explained in the conclusion of this study. For instance, according to Clariana and Wallace (2002), one-item display which features most in computer-based assessment gives greater focus and closure on individual test items, which in turn increases concentration. Such observations are insignificant given that computer-based MCQ administration yielded no significant difference in candidates' performance based on test format (Truell, Alexander and Davis, 2004).

\section{Research on online assessment}

The research by Muwanga-Zake (2006) involved downloading ready-made educational software from the internet for use in diagnostic assessment of some South African Grade 10 Physical Science multiple-choice responses. The programs had the capacity to administer, record and mark assessment tasks as well provide instant diagnostic feedback to learners. About thirteen learners from each of the two secondary schools selected evaluated the software program individually in the computer laboratory. Responses of their opinions to the computerized assessment were captured in a short questionnaire administered at the end of the evaluation session. The results of the study revealed that the learners did not find the test intimidating, as is often the case with pen-and-paper tests. Instead, they found it highly motivating. Indeed learners have been known to prefer a computer as an instrument of assessment rather than a human being, as is the case in pen-and-paper tests.

In Thailand, a study by Maneekhao, Jaturapitakkul, Todd and Tepsuriwong (2006) was concerned about the development of a computer-based test for assessing English as a Second Language to Engineers and Technicians. 
The test was developed using the program Flash, an application software program well-suited for developing animated software programs. By using Flash, innovative and highly interactive test items like those with animations and sound were realised. Both their prototype and final version of the software program were evaluated by engineering students from a nearby university. The assessment was summative in nature and composed entirely of MCQs. A questionnaire was used to gather respondents' opinion after the evaluation process. The research findings were that computer-based assessments offered more than just a convenient mode of testing, but a platform for dynamic and interactive assessments.

Finally, a research by Dolan, Hall, Banerjee, Chun and Strangman (2005) focused mainly on developing an educational software program in Hypertext Markup Language (HTML) for assessing high school English language comprehension. The use of HTML clearly showed the intention of using the internet for running the program. The program was testing MCQs based on the passage displayed on the same page on the screen. The finding was that computer-based tests are effective means of testing reading than the traditional pen-and-paper format. Nevertheless, from experience, long passages which need scrolling on the computer screen possess a challenge for computerized comprehension questions because constant scrolling back and forth can create an inconvenience to the candidates, often leading to loss of focus. Hence, short MCQs are the most logical type of questions for computerized assessment and furthermore, their marking is almost straightforward (Wragg, 2001). Questions with predetermined answers are a perfect treat for automated programs. A traditional mathematical solution can be conceived as one of the privileged approach to learning the subject in that solutions can clearly be right or wrong. The Grade 7 mathematics Paper One examination paper in Zimbabwe is entirely composed of multiple-choice questions, which makes it advantageous to use computer technology for fast and effective assessment. As also noticeable from literature is the fact that different programming languages can be used for online assessment, differing with functionality and programmer's expertise. Trainee mathematics teachers at Brock University in Canada used Visual Basic for their coursework projects (Muller, 2004) user-friendly computer programs intended for teaching and learning of mathematics. By branching into programming, mathematics educators can strive to guarantee availability of their own content-focused software at minimum cost. These could in turn be used for classroom practice, without over-reliance on independent and international commercial software developers. Mathematics educators by coming to the forefront of educational software programming can, to some extent, increase the effective use of computers otherwise under-utilised in a number of schools in Zimbabwe.

\section{Research Design}

Computers are completely dependent upon the instructions that the minds of people give to them. These instructions are in the form of written down statements that the computer can read, interpret and execute. The series of instructions are called software and the art of writing them is called programming (Bennet, 1999). The ability to adhere to written instructions makes computers unique among other electronic machines (Wang, 2002). A programmer is a person who solves problems by carefully analyzing them, develop plans for solving them and write programs that instruct the computer on how to execute the plan. Without a programmer, a computer is useless (Schneider, 2004). A situational analysis of multiple-choice assessment in Zimbabwe points to a gap in use of computer-based mode of assessment countrywide. With the mightiness of computer programming mentioned above, realization computer software has been possible. Initially, an on-the-paper design was made of the intended software, together with the content material that was to be embodied in thereto, of which the current paper-based Grade Seven Mathematics Paper One examination formed the basis the design stage. The design was then transformed to a workable and interactive software program through basic programming skills using Visual Basic VI programming language. The task was broken into sub-problems, like developing of interface and coding of functionalities to make software interactive. These were meticulously merged at the end leading to the evaluation version of the final product.

The moment all the functionalities were activated, a test-run for that near-finished program was piloted at two primary schools by about 60 learners. The aim of piloting was to get feedback from the intended users so that improvements could be done where possible. Eventually, the final version of the software program was field-tested to 120 Grade Seven learners and their teachers based at four primary schools in the town of Bindura, Zimbabwe. The choices of the sampled schools based on availability of learners' computer laboratories at that time. In the evaluation process, the software program was not evaluated in its own merit but according to its actual use in intended educational setting as advised by Passey and Samways (1997). An observational schedule and learner and teacher questionnaires were the only instruments used to collect respondents' opinion on the versatility of software program. Mostly closed questions comprised the learners' questionnaire, taking into 
consideration their tender age and scope, but a number of open-ended questions comprised teachers' questionnaire.

\section{Findings}

A simple-to-use software program was developed using Visual Basic VI according to one of the research questions. Executing the software would see assessment items vividly displayed on the screen, one at a time, as illustrated in Figure 1 below. The candidates' answers were captured and saved at the click of a button "submit", and then punctilious marked and instantly scored. Time countdown was shown in the top right corner of the screen, as well as the candidate's login name. To bar candidates from working beyond the allocated time, the software shuts down automatically when the time allocated for the test expires. The program always runs in full-screen mode, in part to eliminate possible distractions from other computer programs. Should candidates have need of viewing software instructions at any time, they did so by clicking the Help button. Navigation of the test is by the Next and Back buttons. Should a candidate complete the test before the allocated time, clicking the Submit button terminates the test and submits answers for marking. The Quit button enables candidates to quit the assessment at any time should they be ill or something serious occurs. The Time button toggles screen time display, should continuous display of time countdown on the screen make some candidates kind of nervous. The program outputs a number of files, the most important one being the file for candidates' scores, displayed in Figure 2 below. Pseudonyms are used to protect the identity of the trial candidates. As shown in Figure 2, the file lists the date and time of assessment, candidate name and number as well as the score obtained as a percentage. A file similar to this would be automatically forwarded to the examination board from each of the assessment centres.

After assessing the viability of the program to assess and record MCQs online it was necessary to assess the views of teachers on the usefulness of the software based on their observations of learners' attitudes. The teachers' responses on the Likert type questionnaire are shown in Table 1. The results of Table 1 show the participating teachers' enthusiasm of the use of the software as they selected the strongly agreed and agreed categories only. The Likert type responses were corroborated by responses during the interview. The teachers' verbatim responses to some interview questions were: “...the software should be extended to cover other subject areas (Teacher 8), “... more such software are highly recommended in schools, since at the moment, there are hardly any" (Teacher 3), “... CBTs should be implemented forthwith" (Teacher 9) and ".... the software is good and effective" (Teacher 1). Some challenges that teachers felt were associated with the implementation of online assessment were identified as "...the problems of power cuts and poor repair-services to computers are potential drawbacks to computerized assessment" (Teacher 4), and "... the sitting arrangements should be in such a way that test-takers do not peep onto one another's screen to minimize copying" (Teacher 7).

\section{Discussion}

Summative Grade 7 assessments are very important for learners, parents and schools in Zimbabwe because the results are used to place learners to appropriate secondary schools for Form 1. The summative assessments in four subjects are usually written at the beginning of October of each year to enable processing the results so that they are out by mid-December so that learners can be enrolled for Form 1 at the beginning of January of the following year. After passing written entrance examinations for Form 1 places, private and mission schools in Zimbabwe put an extra condition that prospective learners have to pass very well in the Grade 7 summative assessments in the subjects of English and mathematics. The anxiety that is associated with Grade 7 assessment results are usually very high due to the multiple purposes of the results so much that speed in processing the assessments may go a long way to reduce the anxious moments of learners, parents and schools. Online assessment of the MCQs as part of the examinations when used to replace or complement the use of optical scanner readers (currently in use) may reduce the period of processing the examinations. Online assessments based on findings from this study were received well by schools that were used for piloting the software so designed.

In questionnaire responses both learners and teachers confirmed that the program was indeed simple to use, including those who had little or no prior computer experience. Candidates' time was saved enormously by taking assessment in computerized format, to the extent that one teacher commented that the duration for the computer test should be reduced relative to the paper-based counterpart. Coupled with this, selecting and changing answers was easy, fast and neat in the computerized test. In the traditional pen-and-paper test, candidates painstakingly shade lozenges corresponding to one of the multiple-choice responses, and changing a response entails completely erasing the lozenge and re-shading another one. Moreover, contrary to serious cases 
where candidates' answers are disqualified because two responses have been chosen, the software program make-up simple does not permit selection of more than one response per each item.

Though candidates' performance should, in theory vary by method of assessment whether paper-based or computer-based, it was discovered that certain features of the computerized test potentially led candidates to perform better. For example, as also noted by Clariana and Wallace (2002) one-item display always leads to greater concentration and focus, which may provide an advantage or likelihood of performing better than those candidates using pen-and-paper on the same assessment. Also high levels of motivation and interest that may grip candidates throughout a computer-based assessment delivery may give them an advantageous edge on answering the questions. The teachers in the study also agreed that candidates' concentration was high in the online mode of assessment. This opinion was also evident in the observation schedule which revealed that candidates maintained high concentration throughout assessment delivery. In addition, remaining time at the end of the assessment was gainfully used to review item responses. In computer-based assessments screen resolution, font size and colour may significantly improve the appearance of test items relative to the black-and-white colours of paper-based assessments. As was also noted by Russell (1999), these slight changes in item appearances can positively influence performance on those particular items. The teachers in the study agreed that the program was appealing to the eye, to the effect that candidates' interest was captivated whenever they interacted with the software program. Indeed the program was awash with full-colour graphics and matching font colours, a perfect treat for primary school learners. As in all summative assessments, issues of test security are of utmost importance; these are guaranteed as the assessment items can only be available online during the allocated time of writing. Teachers at each of the four schools' visited consented that test security features were good, both before and after the assessments. Pass-codes, only to be made available to candidates on the examination day practically deny access to the test to anyone prior to the day of assessment day. Immediately after the assessment, scores are automatically computed, and possibly mailed electronically to the examination centre by the program itself, thwarting any attempts by school authorities to temper with candidates' work.

The software program, just like any automated program, executes consistently every time it is invoked, with a next to zero margin of error. Both teachers and learners admitted that the software was highly reliable in its manner of assessment of candidates' mathematical knowledge, hence quite effective at assessing the Mathematics Paper One examination. Finally, comments by both teachers to open-ended questions reiterated that the computer-based assessment was quite user-friendly and simple to use. Accordingly, teachers were of the idea that the software should be broadened to include assessments of other subject areas, not just mathematics. Diagnostic and formative software programs with suggested solutions to activities were identified as useful strategies to motivate students to learn mathematics and other subjects. Furthermore, teachers pointed out that the software program should be implemented immediately, though they preferred it as formative assessment. The main reason for this was the fact that some these teachers barely have subject-based software to expose their learners to during the once-a-week computer lessons.

\section{Conclusion}

There are some limitations on the use of online assessment in Zimbabwe such as availability of computers and the internet. The model used to introduce calculators in the ' $\mathrm{O}$ ' Level mathematics syllabus 4028 (Nyaumwe, 2006) can provide insight on how to implement online assessment in the country. Due to the prohibitive cost of scientific calculators in the 1990s two 'O' Level mathematics syllabi existed in Zimbabwe namely, the calculator version (4028) and the non-calculator version 4008. Candidates learnt the same content and wrote the same examinations that were marked differently. The disparity in the pass rates in favor of the calculator version forced schools to adjust their budgets in order to offer the calculator version syllabus. In a similar way online Grade 7 assessment MCQs can initially be offered by those schools with the facilities and other schools can make independent judgments on when to stop hard copy assessments.

Another limitation of the study is the small sample size used and the influence it has on the significance and generalizability of the findings. Nevertheless, the findings remain illuminating. Firstly, the software program was successfully developed using Visual Basic 6 programming language, quite portable and installed with ease on most computers of the schools involved in the field testing. Grade 7 teachers and their learners agreed that the program was appealing to the eye and simple to use. The findings of this study indicated that both teachers and learners were enthusiastic to engage the software program in mathematics MCQ assessment, and developing more such programs may change the face of assessment in Zimbabwe. According to Truell, Alexander and Davis (2004), computer-based assessments by default offer assessment mode benefits to candidates, such as single-item display and good visualisation, which, to some extent, boost their performance. A computer heightens learners' interest in test-taking (McIntosh \& Stacey, 2000), which in turn can help to reduce mathematics-phobia amongst 
learners. Computer-based assessments certainly have a bright future in Zimbabwe and should be implemented forthwith where possible, as highlighted by the teachers at each of the four schools involved in the field testing.

Teachers expressed opinions on expanding computer-based assessments to incorporate formative assessments as a precursor to summative examinations at the end of the year. As for the recommendations of this study, future researches can develop computer-based assessments that do not literary replicate paper-based tests in order to give room for innovative and interactive assessment items which obviously may not possible in paper-based tests (McFarlane, 2001). Computer-based assessments which emanate directly from paper-based tests tend to be restricted in what they can do (Poggio, Glasnapp, Yang \& Poggio, 2005). Again, there is need to develop formative and/or diagnostic assessments prior to summative ones so that candidates can get acquainted with the dynamics of online assessment before encountering them in summative assessments. The present study opened up debate on the potential of online assessment in Zimbabwe. Future studies on this debate may focus on the possible logistics of implementation by ZIMSEC and schools, possible challenges and stakeholders' attitudes in order to begin to understand how online assessment can best be implemented in Zimbabwe.

\section{References}

Bennet, F. (1999). Computers as Tutors: Solving the crisis in Education. [Online] Available: http://www.cris.com/ faben1 (July 28, 2007)

Bennett, R.E. (1998). Using new technologies to improve assessment. Princeton: Educational Testing Service.

Brown, P.J. (2000). Findings of the 1999-2000 Reading Field Test: Inclusive Comprehensive Assessment System. Newark: Delaware Educational Research and Development Centre.

Brumbaugh, D.K., \& Rock, D. (2001). Teaching in Secondary School Mathematics: Methods, Applications, Technology and History. London: Lawrence Erlbaum Associates.

Cawthera, A. (2005). Computers in Secondary schools in Developing Countries: Costs and Other Issues. [Online] Available: http://www.worldbank.org/worlslinks/english/cawthera.htm (September 27, 2007)

Clariana, R., \& Wallace, P. (2002). Paper-based versus computer-based assessment: Key factors associated with the test mode effect. British Journal of Educational Technology, 33(5), 593-602. http://dx.doi.org/10.1111/1467-8535.00294

Dolan, R. P., Hall, T. E., Banerjee, M., Chun, E., \& Strangman, N. (2005). Applying principles of universal design to test delivery: The effect of computer-based read-aloud on test performance of high school students with learning disabilities. Journal of Technology, Learning, and Assessment, 3 (7), 100-112.

Kubiszu, T., \& Borich, G. (1993). Educational Testing and Measurement. New York: HarperCollins College Publishers.

Linn, D. (2002). Using Electronic Assessment to measure Students' Performance. Princeton: NGA Centre for Best Practices.

Maneekhao, K., Jaturapitakkul, N., Todd, R.W., \& Tepsuriwong, S. (2006). Developing an Innovative Computer-based Test. Prospect, 21 (2), 34-46.

McFarlane, A. (2001). Perspectives on the Relationships between ICT and Assessment. Journal of Computer Assisted Learning, 21(6), 419-429.

McIntosh, J., \& Stacey, K. (2000). Designing Constructivist Computer Games for Teaching about Decimal Numbers. In Mathematics Education Research Group of Australia, Mathematics Education Beyond 2000 Volume 1. Perth: Mathematics Education Research Group of Australia.

Muller, E.R. (Ed.). (2004). Future teachers use Technology to Explore Mathematics Concept Development: Proceedings of the ICME 10th Congress. Copenhagen.

Muwanga-Zake, J.W.F. (2006). Applications of Computer-aided Assessment in the diagnosis of Science Learning and Teaching. [Online] Available: http://ijedict.dec.uwi.edu/viewarticle.php?id=226\&layout=html (March 17, 2011)

Nyaumwe, L. J. (2006). Investigating Zimbabwean mathematics teachers' dispositions on the 'O' Level calculator syllabus 4028. South African Journal of Education, 26(1), 39-47.

Passey, D., \& Samways, B. (Eds.). (1997). Information Technology: Supporting Change through Teacher Education. London: Chapman and Hall. 
Poggio, J., Glasnapp, D. R., Yang, X., \& Poggio, A. J. (2005). A comparative evaluation of score results from computerized and paper and pencil mathematics testing in a large scale state assessment program. Journal of Technology, Learning, and Assessment, 3(6), 200-211.

Russell, M. (1999). Testing writing on Computers: A follow-up study Comparing Performance on Computer and on Paper. Educational Policy Analysis Archives, 7(20), 120-135.

Schneider, D.I. (2004). Introduction to Programming using Visual Basic 6.0 Update Edition. Upper Saddle River: Pearson Educational.

Scholtz, A. (2007). An Analysis of the Impact of an Authentic Assessment Strategy in a Technology-mediated Constructivist Classroom. International Journal of Education and Development, 3(4), 42-53.

Truell, A.D., Alexander, M.W., \& Davis, R.E. (2004). Comparing Post-secondary Marketing Students' Performance on Computer-Based and Handwritten Essay Tests. Journal of Careers and Technical Education, 29(2), 69-78.

Wang, S., Jiao, H., Young M.J., Brooks, T., \& Olson, J. (2007). Comparability of Computer-based and Paper-and-Pencil Testing in K12 Reading Assessment: A Meta-analysis. [Online] Available: http://epm.sagepub.com/cgi/content/abstract/68/1/5 (February 18, 2008)

Wang, W. (2002). Visual Basic.net for Dummies. New York: Hungry Minds.

Wragg, S.C. (2001). Assessment and Learning in the Secondary School. London: Routledge.

Zimonline. (2007). Zimbabwe Exam Body Runs out of Funds to Mark Exams. [Online] Available: http://www.zimonline.co.za/Article.aspx?ArticleId=2210 (October 30, 2007)

Table 1. Teachers' responses to the Likert-type questions

\begin{tabular}{|l|l|l|l|l|l|}
\hline Question & SA & A & U & D & SD \\
\hline 1. The software is appealing to the eye & 7 & 3 & 0 & 0 & 0 \\
\hline 2. Changing answers in CBTs is fast and easy. & 5 & 5 & 0 & 0 & 0 \\
\hline 3. CBTs captivate candidates' interest in test-taking. & 9 & 1 & 0 & 0 & 0 \\
\hline 4. Lack of computing skills hinders candidates' performance. & 1 & 3 & 1 & 0 & 0 \\
\hline 5. The future of CBTs is bright in Zimbabwe. & 3 & 6 & 0 & 1 & 0 \\
\hline 6. Shortage of computers in schools hinder progress of CBTs. & 7 & 3 & 0 & 0 & 0 \\
\hline 7. Candidates' concentration is high in CBTs. & 6 & 4 & 0 & 0 & 0 \\
\hline 8. CBTs are secure in terms of cheating and leakages. & 3 & 5 & 2 & 0 & 0 \\
\hline 9. The assessment software program is simple to use & 4 & 6 & 0 & 0 & 0 \\
\hline 10. Instructions are clear, precise and easy to understand. & 4 & 6 & 0 & 0 & 0 \\
\hline
\end{tabular}




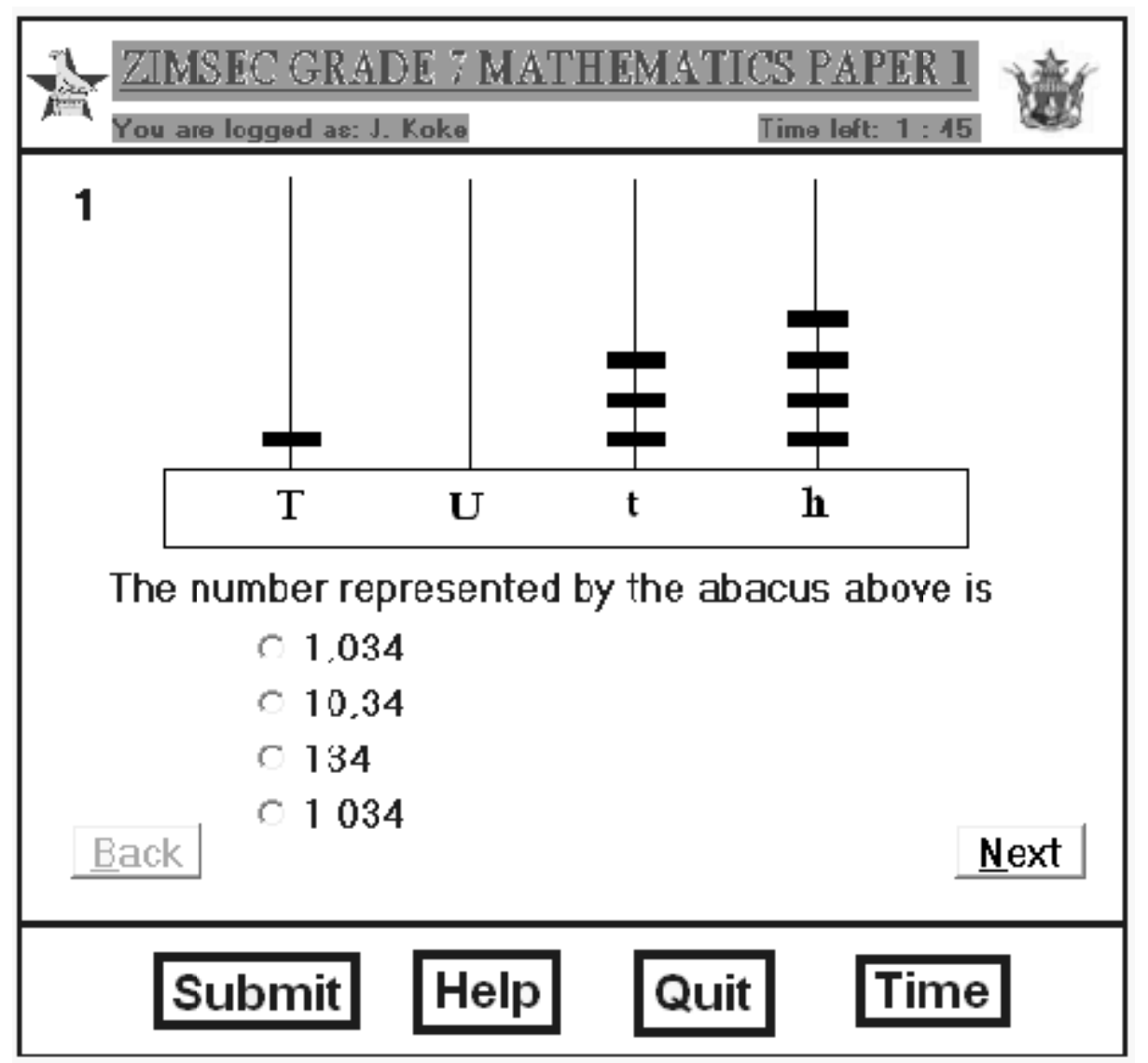

Figure 1. Appearance of one of an assessment item on the screen

\begin{tabular}{|c|c|c|c|c|}
\hline [ scores_file - Notepad & & & & $\square \square x$ \\
\hline \multicolumn{5}{|l|}{ File Eddit Format Yiew Help } \\
\hline $3 / 28 / 2008 \quad 2: 43: 22 \mathrm{AM}$ & Tendai & Mhaka & 070880122 & $60 \%$ \\
\hline $3 / 28 / 20082: 45: 53 \mathrm{AM}$ & Chenge & Mutamba & 070880129 & $30 \%$ \\
\hline 3/28/2008 2:47:58 AM & John & Koke & 070880125 & $90 \%$ \\
\hline 3/28/2008 11:12:25 AM & Peter & Haka & 070880126 & $20 \%$ \\
\hline 3/28/2008 5:16:07 PM & Steven & Mordecai & 070880130 & $90 \%$ \\
\hline $3 / 28 / 2008 \quad 2: 17: 07 \mathrm{PM}$ & Ron & Guranyika & 070880128 & $0 \%$ \\
\hline
\end{tabular}

Figure 2. Program output file showing candidate's details 